UDC: 616.8-009.832-092:616.831-005.1

\title{
STUDYING OF VERTIGO IN ACUTE ISCHEMIC BRAIN DISORDERS IN THE VERTEBROBASILAR SYSTEM
}

\section{(C) S. Fedorchenko}

The work is devoted to the study of vertigo in patients with acute ischemic brain disorders.

Aim - studying the role of acute cerebral ischemia in the formation of vertigo in patients with focal and transient ischemic deficits in the vertebrobasilar system.

Material and methods. The study is based on the results of a prospective analysis of 37 patients with acute cerebral pathology in vertebrobasilar territory. The patients were examined and treated in the neurological departments "Kharkiv State Clinical Hospital №7》. We used clinical and neurological method, investigated the condition of the main arteries of the head, digital ultrasonic diagnostic scanning system. Brain structure was investigated on MRI. The study showed, that in acute manifestations of vascular disease in the vertebrobasilar system isolated vertigo is rare, most often a combination of vertigo occurs with neurological symptoms.

Result. Neuroimaging results did not conclusively interpreted the relationship of dizziness with acute cerebral ischemia in the vertebrobasilar system; further research with the assistance of modern technology in the form of magnetic resonance angiography of brain vessels, duplex ultrasonography, and statistical methods.

The prevalence of high degree of stenosis (50\% to $85 \%$ ) of arteries of vertebrobasilar system at the ultrasound indicates a high risk of stroke in the population and the need to optimize the preventive measures.

Conclusions. To solve the problems of early diagnosis and prevention of vertigo in acute ischemic cerebral disorders the program of preventive measures cerebrovascular disease should include screening ultrasound for the detection of this pathology already at an early (asymptomatic) stage of the disease

Keywords: Vertigo, acute cerebral ischemia, vertebrobasilar system, Doppler ultrasound, MRI study

Вивчалася роль гострої ішемії головного мозку в вертебробазилярній системі у формуванні запаморочення у 37 обстежених хворих. Використовували клінічний та інструментальні методи. Виявлено: при гострих проявах судинної патологї в вертебробазилярному басейні ізольоване вестибулярне запаморочення зустрічається рідко, частіше спостерігається поєднання системного запаморочення з неврологічними симптомами

Ключові слова: запаморочення, гостра ішемія головного мозку, вертебробазилярна система, УЗДГ, МРТ-дослідження

\section{Introduction}

Vertigo - one of the most difficult and controversial issues of modern medicine in general and neuroscience particularly. Despite the fact that the vertigo is studied over a long period of time, many questions remain unresolved or are in the process of discussion.

The mechanism of development of vertigo in cerebrovascular diseases is diverse. Often, vertigo is one of the first signs of vascular insufficiency, as persistent and transient circulatory disorders of the central or peripheral parts of the vestibular system [1-5].

In practice, a neurologist observed acutely occurring vertigo (systemic), caused by a disorder of cerebral circulation in the vessels of vertebrobasilar (VB) system $[2-4,6]$.

Acute vertigo is often the cause of emergency hospital admissions for neurological department with a preliminary diagnosis of "acute ischemic stroke in the vertebrobasilar system" [4, 7]. A large study showed that vertigo accounts for 3,2-3,3\% of all emergency hospital admissions [8, 9].

In patients, who have have been referred to the neurologist with non specific dizziness in primary care, cerebrovascular diseases were detected in 3,5\% of cases; at the same time the stroke as the cause of dizziness was diagnosed in $0,8 \%$ of patients [10].
Clinical management and outcome of patients with vertigo depends on the cause and extend, as well as localization of ischemic damage. In acute cerebrovascular accidents (CVA) in the vertebrobasilar territory there is a high probability of acute death, and with the rapid deterioration of neurological symptoms and recurrent stroke [10-14].

Atherosclerosis, atrial fibrillation and hypertension contributing to the formation of an arterial blood clot are the most often causes of acute cerebral ischemia. Against the background of chronic cerebral ischemia of vertebrobasilar system an acute stroke often developed, which leads to overdiagnosis if there are complaints on vertigo and imbalance [15]. Repeated stroke and transient ischemic attacks in the vertebrobasilary system causes progressive, diffuse or focal lesions of the brainstem and cerebellum [16-19].

Cerebrovascular etiology of sudden onset of vertigo indicates a lesion of the central vestibular system usually, while in lesions of peripheral vestibular system vertigo develops slowly [20].

Early diagnosis of the causes of vertigo is a particular importance, as it allows a timely manner to determine the treatment strategy, a program of rehabilitation and preventive measures, which increases their efficiency generally. 
The above demonstrates the need for the study of the diagnostic features of vertigo, identification of its causes and appropriate treatment strategy.

\section{Case presentation}

This article is a fragment of a comprehensive study of patients with vertigo. Recent data studying of the dizziness symptom indicates the complexity of the diagnosis of this phenomenon and identifying of its causes. The latter is important, because it provides strategies for effective therapeutic measures.

The emphasis on patients with cerebrovascular disease in the vertebrobasilar system is made due to the fact, that the symptom in this disease is an obligate, but the reason for its occurrence is not always fraught with ischemic brain damage. There are structures (brainstem, cerebellum, pons cerebelli and basal nuclei of the skull base) in the range of vertebrobasilar system, which damage causes the vertigo. Question of the vertigo differentiation causes remains a priority, but loses its paramount importance at the stage of emergency admission. Formulated in previous studies principles conducted with vertigo overdiagnosis as the reasons are related to the outpatient medical care patients [10], which significantly differs from the present study.

\section{Aim of research}

Studying the role of acute cerebral ischemia in the formation of dizziness in patients with focal and transient ischemic deficits in the vertebrobasilar system.

\section{Materials and methods}

The study is based on the results of a prospective analysis of 37 patients with acute cerebral pathology in the vertebrobasilar territory. The patients were examined and treated in the neurological departments of "Kharkiv State Clinical Hospital № 7».

In addition to clinical and neurological methods, we studied the state of the main arteries of the head (MAH), a digital diagnostic ultrasound scanning system SONOLINE G40 (SIEMENS). The estimation of these indicators is carried out: a linear systolic flow velocity (LSFV), the state of the vessel lumen, the state of intima-media complex, the presence of vascular deformations, the presence of atherosclerotic plaques in view of their quality characteristics and sizes. Brain structure was investigated on MRI - Siemens AG company tomograph 2008 b, serial number 48593 , the software NUMARIS/4, version syngo MR C12, the device is licensed for HEMO MEDICA KHARKOV, ID: 029; with a magnetic field strength of $1.5 \mathrm{~T}$, the tension gradient fields: 80/150 SLEW RATE. We used single-channel head coil CRM QUAD HEAD COIL MODEL 46-2821186202. The data obtained are processed by office package Open Office). Statistical method: standard declination.

\section{Results}

To achieve this goal, the patients were divided into 2 groups:
1 group - patients with ischemic stroke (IS) 16 patients;

2 group - patients with transient ischemic attack (TIA) -21 patients.

The treatment groups were comparable by age, sex and risk factors. The survey consisted of patients from 40 to 85 years, the average age was $65,4 \pm 19,9$ of them men $-48,6 \pm 8,3 \%$, women $-51,3 \pm 8,3 \%$.

The average age in the 1st group was $64,4 \pm$ $\pm 18,9$ years; in the 2 nd group $-63,1 \pm 21,1$ years. The 1st group included $9(56,2 \pm 12,4 \%)$ males and $7(43,7 \pm$ $\pm 12,4 \%)$ women; in the 2 nd group - $9(42,8 \pm 10,7 \%)$ and $12(57,1 \pm 10,7 \%)$, respectively.

In ischemic stroke group male patients dominated $-56,2 \pm 12,4 \%$, the average age was $63,3 \pm 18,0$ years; female patients were noted at $43,7 \pm 12,4 \%$ of cases, the average age varied from $67,6 \pm 25,0$ years. Females in the group of patients with TIA dominated by $-57,1 \pm 10,7 \%$ (mean age $-65,9 \pm 23,0$ years); male patients there were $42,8 \pm 10,7 \%$, the average age was $60,2 \pm 10,5$ years.

Thus, gender analysis of total and age characteristics of the surveyed patients testified that the average age of male patients was $61,2 \pm 12,7$ (range $45-74$ years); female patients $-62,8 \pm 22,6$ (range $40-85$ years). The main part of the male patients were in the age group $50-65$ years $-72,2 \pm 7,5 \%$ of the cases; aged $66-$ 75 years $-27,8 \pm 7,5 \%$; among women age range of features was considerably larger and amounted to 40-85 years; at the same time, the extreme poles of the age indices were observed in single patients.

In general, the group of the largest number of female patients $-73,7 \pm 7,3 \%$ were patients age group $66-$ 85 years; in the range of $40-65$ years, $26,3 \pm 7,3 \%$ of patients were observed.

The pattern of age-related features of examined patients was characterized by the fact that symptom of vertigo in the framework of cerebrovascular pathology is an obligate; less favorable in male patients, which manifests itself in more frequent damage of brain structures (infarctions) and the vulnerability of younger, working-age population.

The cause of stroke in the vertebrobasilar system as hypertension and atherosclerosis of cerebral vessels was high and reached $93,7 \pm 6,0 \%$ and $43,7 \pm 12,4 \%$, respectively.

In the group of patients with ischemic stroke ischemic lesions in vertebrobasilar system in whole were observed. Foci localization in $37,5 \pm 12,0 \%$ cases were in the right middle, posterior cerebral artery or posterior cerebellar artery; a. auditiva interna was involved in the pathological process in $12,5 \pm 8,2 \%$ of cases. Patients with TIA of the total accounted for $76,2 \pm 9,2 \%$ of the cases.

On the background of discirculation encephalopathy (DE) in $71,4 \pm 7,5 \%$ of patients acute stroke has developed. In the group with ischemic stroke discirculation encephalopathy (hypertensive, atherosclerotic) was met in $43,7 \pm 12,4 \%$ of patients. In the group of patients with TIA, hypertension was observed in $85,7 \pm 7,6 \%$ of cases, cerebral vascular atherosclerosis - in $42,9 \pm 10,7 \%$ of cases. 
The core of the clinical picture of the patients was vertigo, which was noted in $100,0+$ $+0 \%$ of patients in both groups. Primary vertigo histories were found in $87,5 \pm 8,2 \%$ of patients with ischemic stroke (first group) and 80,9 $\pm 8,5 \%$ in patients with TIA (second group), repeated - in $12,5 \pm 8,2 \%$ and $19,0 \pm 8,5 \%$ respectively (Table 1).

Other symptoms, including determination of the severity of condition, were such as unsteadiness while walking, which is more pronounced in patients with TIA (2-nd group) $80,9 \pm 8,8 \%$ of the cases and $68,7 \pm 11,9 \%$ of patients with ischemic stroke (1-st group); headache in $47,6 \pm 11,2 \%$ among the patients with TIA was observed and in $37,5 \pm 12,5 \%$ of patients with ischemic stroke. Weakness in the limbs was observed only in patients of the 1st group $-68,7 \pm 11,9 \%$ of the cases. Slurred speech and dysarthria prevailed in patients with ischemic stroke $-43,7 \pm 12,8 \%$ of the cases, in patients with TIA - in $28,6 \pm 10,0 \%$ of patients. The high prevalence of the examined patients presented symptoms such as nausea and vomiting, which are often observed in patients with TIA - in $42,9 \pm 11,0 \%$ and $33,3 \pm 10,5 \%$, respectively; in patients with ischemic stroke to $37,5 \pm 12,5 \%$ and $31,2 \pm 11,9 \%$ of cases. One of the pathognomonic symptoms of vertigo is nystagmus, where its qualitative characteristics are highly important. The detection of this clinical sign during the initial examination was $38,1 \pm 10,8 \%$ of cases in the group with transient ischemic and $37,5 \pm 12,5 \%$ of patients with cerebral infarction. Nystagmus generally was horizontal with fast component to the right, left. Frenzel goggles to detect nystagmus sometimes were used. Subjectively patients reported blurred vision more often in patients of Group $1-18,7 \pm 10,0 \%$, and in individual patients with TIA $-4,8 \pm 4,7 \%$.

Reduced muscle strength and clumsiness noted, to a greater extent in patients of 2 group - 28,6 $6 \pm 10,0 \%$ and $12,5 \pm 8,5 \%$ of cases with IS. Widely represented in the overall clinical picture of patients with TIAs were symptoms such as weakness and fatigue - 33,3 $\pm 10,5 \%$ of the cases, and in rare cases in patients with ischemic stroke $-6,2 \pm 6,2 \%$.

Rare frequency of occurrence in the examined patients had clinical signs such as hearing loss (decreasement), hiccups, diplopia, deviation of the tongue, "flies" in front of eyes, and autonomic symptoms as tachycardia, arrhythmia, anxiety, and emotional lability. Most of them were observed in patients with TIA and were not observed in patients with ischemic stroke.

Of particular importance were performance of coordination of dynamic and static samples, the violation of which was found in almost all patients with TIA $95,2 \pm 4,8 \%$ of cases and was somewhat smaller in the group of patients with ischemic stroke $-81,2 \pm 10,0 \%$.
Table 1

The prevalence of clinical symptoms in the examined patients, $(\%)$

\begin{tabular}{|c|c|c|}
\hline Clinical manifestation & $\begin{array}{c}\text { Group 1 } \\
\text { (patients with } \\
\text { ischemic stroke, } \\
n=16 \text { ) }\end{array}$ & $\begin{array}{c}\text { Group } 2 \\
\text { (patients with TIA, } \\
n=21 \text { ) }\end{array}$ \\
\hline Vertigo & $100 \pm 0$ & $100 \pm 0$ \\
\hline Initial start of the process & $87,5 \pm 8,5$ & $80,9 \pm 8,8$ \\
\hline Repeated episode & $12,5 \pm 8,5$ & $19,0 \pm 8,8$ \\
\hline Unsteadiness & $68,7 \pm 11,9$ & $80,9 \pm 8,8$ \\
\hline Weakness in the limbs & $68,7 \pm 11,9$ & 0 \\
\hline Speech disorder, blurred & $43,7 \pm 12,8$ & $28,6 \pm 10,0$ \\
\hline Headache & $37,5 \pm 12,5$ & $47,6 \pm 11,2$ \\
\hline Nausea & $37,5 \pm 12,5$ & $42,9 \pm 11,0$ \\
\hline Vomiting & $31,2 \pm 11,9$ & $33,3 \pm 10,5$ \\
\hline Nystagmus & $37,5 \pm 12,5$ & $38,1 \pm 10,8$ \\
\hline $\begin{array}{l}\text { Decrease in muscle strength, } \\
\text { awkward }\end{array}$ & $12,5 \pm 8,5$ & $28,6 \pm 10,0$ \\
\hline Blurred vision & $18,7 \pm 10,0$ & $4,8 \pm 4,7$ \\
\hline General weakness, fatigue & $6,2 \pm 6,2$ & $33,3 \pm 10,5$ \\
\hline Hearing decreasement & $6,2 \pm 6,2$ & 0 \\
\hline Tinnitus & $43,7 \pm 12,8$ & $66,7 \pm 10,5$ \\
\hline Hiccups & $6,2 \pm 6,2$ & 0 \\
\hline Diplopia & 0 & $4,8 \pm 4,7$ \\
\hline Deviation of the tongue & 0 & $4,8 \pm 4,7$ \\
\hline «Flies» before the eyes & 0 & $4,8 \pm 4,7$ \\
\hline Tachycardia, arrhythmia & 0 & $4,8 \pm 4,7$ \\
\hline Anxiety, emotional lability & 0 & $9,5 \pm 6,5$ \\
\hline Intention at coordination sample & $81,2 \pm 10,0$ & $95,2 \pm 4,8$ \\
\hline Ataxia in the Romberg position & $81,2 \pm 10,0$ & $95,2 \pm 4,8$ \\
\hline $\begin{array}{l}\text { Results of the CT, MRI: } \\
\text { - focal changes (infarctions)*/ } \\
\text { ischemia changes** } \\
\text { (hypoperfusion); } \\
\text { - DE signs }\end{array}$ & $\begin{array}{l}53,8 \pm 12,8^{*} \\
46,2 \pm 12,8\end{array}$ & $\begin{array}{c}38,5 \pm 10,9 * * \\
61,5 \pm 10,8\end{array}$ \\
\hline
\end{tabular}

ote: * - focal changes (infarctions); **-ischemia changes (hypoperfusion)

\section{Discussion}

The conception of this study was in attempt to identify the role of acute cerebral ischemia in the formation of vertigo through the analysis and comparison of clinical symptoms and the results of instrumental methods.

Neuroimaging studies (MRI of the brain) are one of the most informative diagnostic methods in acute cerebrovascular origin emergencies.

Results showed that in patients with ischemic stroke focal disorders of cerebral infarctions were observed in half of the patients $-53,8 \pm 12,8 \%$ and $46,2 \pm$ $\pm 12,8 \%$ patients recorded the MR signal DE signs. In the

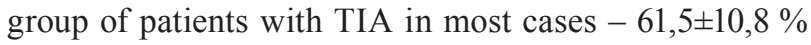
were detected signs of DE as a manifestation of the neurodegenerative processes; in $38,5 \pm 10,9 \%$ patients had non-localized foci of ischemia without serious damage of the nervous tissue.

Ultrasonography of the MAH revealed stenosis or occlusion of large vessels, identified atherosclerotic plaques, blood clot in the vessel (if any). In addition, the measurements of linear and volumetric blood flow velocity, turbulent flow, percent stenosis of vessels, the presence of vascular anomalies - hemodynamically 
significant or insignificant crimps and hypoplasia of vessels were carried out. The identified results of the study showed the presence of widespread and diverse changes and violations of the great vessels in the examined patients (Table 2).

Table 2

The prevalence of alterations in the great vessels of the head in the surveyed patients (according to ultrasonography), $\%$

\begin{tabular}{|c|c|c|}
\hline The clinical manifestations & $\begin{array}{c}\text { Group } 1 \\
\text { (patients with IS, } \\
n=16 \text { ) }\end{array}$ & $\begin{array}{c}\text { Group } 2 \\
\text { (patients with TIA, } \\
n=21 \text { ) }\end{array}$ \\
\hline No revealed pathology & $16,7 \pm 9,3$ & 0 \\
\hline $\begin{array}{l}\text { Tortuosity of the arteries: } \\
\text { - carotid; } \\
\text { - vertebral }\end{array}$ & $\begin{array}{l}50,0 \pm 12,5 \\
25,0 \pm 10,8\end{array}$ & $\begin{array}{c}75,0 \pm 9,4 \\
58,3 \pm 10,7\end{array}$ \\
\hline $\begin{array}{l}\text { Non-physiological turbulence of } \\
\text { the flows }\end{array}$ & $41,7 \pm 12,3$ & $33,3 \pm 10,2$ \\
\hline Vascular dilatation & $16,7 \pm 9,3$ & 0 \\
\hline $\begin{array}{l}\text { Atherosclerosis of } \\
\text { brachiocephalic trunk }\end{array}$ & $66,7 \pm 11,7$ & $66,7 \pm 10,2$ \\
\hline $\begin{array}{l}\text { Atherosclerosis of the main vessels of } \\
\text { the neck }\end{array}$ & $66,7 \pm 11,7$ & $66,7 \pm 10,2$ \\
\hline $\begin{array}{l}\text { The presence of } \\
\text { atherosclerotic plaques }\end{array}$ & $66,7 \pm 11,7$ & $58,3 \pm 10,7$ \\
\hline $\begin{array}{l}\text { Vascular lumen stenosis: } \\
\text { - carotid arteries D/S; } \\
\text { - vertebral arteries; } \\
\text { - Arteries subclavicularis }\end{array}$ & $\begin{array}{c}66,7 \pm 11,7 / 66,7 \pm 11,7 \\
33,3 \pm 11,7 \\
8,3 \pm 6,8\end{array}$ & $\begin{array}{c}92,0 \pm 5,9 / 66,7 \pm 10,2 \\
25,0 \pm 9,4 \\
25,0 \pm 9,4\end{array}$ \\
\hline $\begin{array}{l}\text { Difficulty perfusion } \\
\text { (high resistance of flows) }\end{array}$ & $16,7 \pm 9,3$ & $33,3 \pm 10,2$ \\
\hline $\begin{array}{l}\text { Hypoplasia of the carotid and } \\
\text { vertebral arteries }\end{array}$ & $25,0 \pm 10,8$ & $33,3 \pm 10,2$ \\
\hline «Small» size of the vertebral arteries & $25,0 \pm 10,8$ & $33,3 \pm 10,2$ \\
\hline $\begin{array}{l}\text { Elasticity decrease of the Arteries } \\
\text { sides properties }\end{array}$ & $16,7 \pm 9,3$ & $25,0 \pm 9,4$ \\
\hline reduction of blood flow & $75,0 \pm 10,8$ & $58,3 \pm 10,7$ \\
\hline The overall flow pattern (hypokinetic) & $25,0 \pm 10,8$ & $16,7 \pm 8,0$ \\
\hline $\begin{array}{l}\text { Atypical entrance of the vertebral } \\
\text { artery in the bone canal }\end{array}$ & 0 & $16,7 \pm 8,0$ \\
\hline $\begin{array}{l}\text { Dilation of the jugular and } \\
\text { vertebral veins }\end{array}$ & $50,0 \pm 12,5$ & $33,3 \pm 10,2$ \\
\hline Slowing jugular veins blood flow & $16,7 \pm 9,3$ & $16,7 \pm 8,0$ \\
\hline Compensatory increase of a blood flow & $33,3 \pm 11,7$ & $25,0 \pm 9,4$ \\
\hline
\end{tabular}

In the first group (with IS) pathology was not observed only in $16,7 \pm 9,3 \%$ of patients; in the second group (TIA) these patients were not mentioned at all. Kinking of carotid and vertebral arteries was observed in half and a quarter of patients with ischemic stroke, respectively; in the group with TIA data breach was manifested more often $-75,0 \pm 9,4 \%$ and $58,3 \pm 10,7 \%$, respectively. In patients with focal disorders non-physiological turbulence prevailed $-41,7 \pm 12,3 \%$ of the cases; in patients with transient ischemic - to $33,3 \pm 10,2 \%$. Dilation of blood vessels was observed in only $16,7 \pm 9,3 \%$ of patients with ischemic stroke. Complex of disorders caused by atherosclerotic lesions of the brachiocephalic trunk and the main vessels of the head with the formation of atherosclerotic plaques, regardless of diagnostic accessories (implements), was observed in the majority of examined patients and reached $66,7 \pm 7,8 \%$ of the cases. This prevalence of atherosclerotic lesions is forming a cascade of pathological disorders from both the walls (sides) and the lumen of blood vessels, and blood flow dynamics. Among examined patients stenosis of the carotid arteries was found in $67 \pm 7,8 \%$ of all patients. The transient deficit stenosis of the right carotid artery was observed in $92,0 \pm 5,9 \%$; a quarter of patients had vertebral arteries stenosis and the same number of patients - stenosis of the subclavian arteries. Stenosis of vertebral arteries in patients with the focal deficient group was observed in $33,3 \pm 11,7 \%$, to a lesser extent stenosis of subclavian arteries $(8,3 \pm 6,8 \%)$. Particular importance is the degree of narrowing of the main arteries. In patients with ischemic stroke range of the stenosis right carotid artery varied from $27 \%$ to $69 \%$; stenosis of the left carotid artery ranged from $21 \%$ to $67 \%$ of the total lumen. Stenosis of the vertebral arteries corresponded to $50 \%$, and subclavian arteries $-60 \%$ of the total lumen. In group with TIA level of the right carotid artery stenosis was $21-55 \%$, the left carotid artery $-20-63 \%$; occlusion of the vertebral arteries manifested from $40 \%$ to $85 \%$, with two thirds of patients with occlusion of $80-85 \%$. This represents a prognostically very unfavorable variant and creates the need for the intervention of a vascular surgeon. Stenosis of the subclavian arteries was $27-74 \%$. The above changes caused difficulty perfusion with high flow resistance that prevailed in patients with transient ischemic deficit $33,3 \pm 10,2 \%$ of the cases.

Hypoplasia of the carotid and vertebral arteries, and "small" size of the vertebral arteries were observed in a quarter of patients with IS and $33,3 \pm 10,2 \%$ of patients with TIA in both cases respectively. Reduction of the elastic properties of the arterial walls prevailed in the second group of patients $-25,0 \pm 9,4 \%$ of the cases; decrease in blood flow was shown in $75,0 \pm 10,8 \%$ of patients with focal disorders and $58,3 \pm 10,7 \%$ with transient disturbances. The total blood flow as the hypokinetic pattern was observed in $25,0 \pm 10,8 \%$ of patients of the 1st group and in $16,7 \pm 8,0 \%$ of cases in the 2 nd; the same number of patients in group 2 showed atypical entrance of the vertebral artery in the bony canal at the level of C5.

Hemodynamic disorders, accompanied by dilatation of the jugular and vertebral veins in $50,0 \pm 12,5 \%$ and $33,3 \pm 10,2 \%$ of the cases in the first and second groups, respectively, with the slowdown jugular vein blood flow 
in $16,7 \pm 9,3 \%$ and $16,7 \pm 8,0 \%$ of patients in each group respectively, and a compensatory increase in blood flow in $33,3 \pm 11,7 \%$ of patients with IS and $25,0 \pm 9,4 \%$ with TIA.

Thus, according to the pathogenesis of acute stroke in the vertebrobasilar arterial system, the formation of vertigo causes transient or persistent hypoperfusion of the labyrinth, the vestibular nuclei or cerebellum. Among the investigated patients $12,5 \%$ of the cases, when a. auditiva interna to the disease process was involved and $2,1 \%$ of the cases with damage to the cerebellum were diagnosed. The emergence of dizziness determines the need for complex research on early diagnostic measures.

\section{Conclusions}

1. In acute manifestations of vascular disease in the vertebrobasilar system isolated vestibular vertigo is rare, most often a combination of vertigo occurs with neurological symptoms.

2 . The imaging results did not conclusively interpreted the relationship of dizziness with acute cerebral ischemia in the vertebrobasilar system, but in certain cases allow identify the cause of vertigo; further research with the assistance of modern technology in the form of magnetic resonance angiography of brain vessels, duplex ultrasonography, and statistical methods.

3. The prevalence of a high degree of stenosis (50\% to $85 \%$ ) arteries of the vertebrobasilar system at the ultrasound indicates a high risk of stroke in the population and the need to optimize the preventive measures.

4. To solve the problems of early diagnosis and prevention of vertigo in acute ischemic cerebral disorders in a program of preventive measures cerebrovascular disease should include screening ultrasound for the detection of this pathology already at an early (asymptomatic) stage of the disease.

\section{References}

1. Damulin, I. V. Stroke and neuroplasticity [Text] / I. V. Damulin, E. V. Ekusheva // Journal of Neurology and Psychiatry. S.S. Korsakov. - 2014. - Vol. 114, Issue 12. - P. 136. doi: 10.17116/jnevro2014114121136-142

2. Edlow, J. A. Using the Physical Examination to Diagnose Patients with Acute Dizziness and Vertigo [Text] / J. A. Edlow, D. Newman-Toker // The Journal of Emergency Medicine. - 2016. - Vol. 50, Issue 4. - P. 617-628. doi: 10.1016/ j.jemermed.2015.10.040

3. Lee, S.-H. Acute Diagnosis and Management of Stroke Presenting Dizziness or Vertigo [Text] / S.-H. Lee, J.-S. Kim // Neurologic Clinics. - 2015. - Vol. 33, Issue 3. - P. 687-698. doi: 10.1016/j.ncl.2015.04.006

4. Abdulina, O. V. Frequency, causes, differential diagnosis, treatment and prognosis of acute vestibular vertigo in the emergency neurology [Text]: abstract. dis. ... PhD. / O.V. Abdulina. - Moscow, 2008. -32 p.

5. Park, H. Vertigo [Text] / H. Park, H. Kim, M. Cha, I. Koh // Yonsei Med J. - 2013. - Vol. 54, Issue 6. - P. 1538-1541.

6. Alekseeva, N. S. Lack of blood flow in the vertebrobasilar system and peripheral cochleovestibular syndromes [Text] / N. S. Alekseeva // Atmosphere-Nervous Diseases. 2005. - Vol. 1. - P. 20-24.
7. Caplan, L. R. New England Medical Center Posterior Circulation Registry [Text] / L. R. Caplan, R. J. Wityk, T. A. Glass et. al. // Ann. Neurol. - 2004. - Vol. 56. P. 389-398.

8. Newman-Toker, D. E. Spectrum of dizziness visits to US emergency departments: crosssectional analysis from a nationally representative sample [Text] / D. E. Newman-Toker, Y.-H. Hsieh, C. A. Camargo, A. J. Pelletier, G. T. Butchy, J. A. Edlow // Mayo Clinic Proceedings. - 2008. -Vol. 83, Issue 7. - P. 765-775. doi: 10.4065/83.7.765

9. Kerber, K. A. Stroke among patients with dizziness, vertigo, and imbalance in the emergency department: a population-based study [Text] / K. A. Kerber, D. L. Brown, L. D. Lisabeth, M. A. Smith, L. B. Morgenstern // Stroke. 2006. - Vol. 37, Issue 10. - P. 2484-2487. doi: 10.1161/01. str.0000240329.48263.0d

10. Zamergrad, M. V. Age-related aspects of diagnosis and treatment of vertigo [Text]: Diss ... Doctor. Med. Sciences / M. V. Zamergrad. - Moscow, 2015. - 243 p.

11. Parfenov, V. A. Diagnosis and treatment of vertigo in outpatients [Text] / V. A. Parfenov, N. V. Bestuzhev // Doctor. 2012. - Issue 12. - P. 18-21.

12. Parfenov, V. A. Vertigo: Diagnosis and Treatment, common diagnostic mistakes [Text] / V. A. Parfenov, M. V. Zamergrad, O. A. Melnikov. - Moscow: Medical Information Agency, 2011. - 192 p.

13. Zhuravleva, M. V. Modern aspects of treatment of vestibular and coordination disorders [Text] / M. V. Zhuravleva // Consilium Medicum Ukraina. - 2011. - Issue 2. - P. 22-26.

14. Parfenov, V. A. Peripheral vestibulopathy under the guise of stroke [Text] / V. A. Parfyonov, O. V. Abdulina, M. V. Zamergrad // Journal of Neurology. - 2005. - Issue 6. P. 28-32.

15. Parfenov, V. A. Vertigo [Text] / V. A. Parfenov, M. V. Zamergrad, O. A. Melnikov, T. T. Batysheva // Guidelines. Medical News Agency. - Moscow, 2011. - P. 14.

16. Yavorskaya, V. A. Clinical and pathologic comparison of different subtypes of ischemic stroke [Text] / V. A. Yavorskaya, V. V. Hvisyuk, O. B. Cooper et. al. // Ukrainsky News of Psihonevrology. - 2015. - Vol. 23. - P. 53-57.

17. Treschinskaya, M. A. Modern possibilities of the complex therapy of hypertensive encephalopathy [Text] / M. A. Treschinskaya // News of Medicine and Pharmacy in Ukraine. - 2008. - Issue 2 (233).

18. Oshchepkova, E. V. Hypertensive encephalopathy [Text] / E. V. Oshchepkova // Consilium Medicum. - 2004. Vol. 3, Issue 3.

19. Homazyuk, T. A. General practice [Text] / T. A. Homazyuk, K. Y. Egorov // Health Protection of Ukraine XXI century. - 2010. - Issue 3 (14). - P. 25-26.

20. Howell Collie, M. J. Differentiating Benign Paroxysmal Positional Vertigo From Other Causes of Dizziness [Text] / M. J. Howell Collie, A. R. Ramsey // The Journal for Nurse Practitioners. - 2014. - Vol. 10, Issue 6. - P. 393-400. doi: 10.1016/ j.nurpra.2014.03.008

\section{References}

1. Damulin, I. V., Ekusheva, E. V. (2014). Stroke and neuroplasticity. Zhurnal Nevrologii i Psikhiatrii Im. S. S. Korsakova, 114 (12), 136. doi: 10.17116/jnevro2014114121136-142 
2. Edlow, J. A., Newman-Toker, D. (2016). Using the Physical Examination to Diagnose Patients with Acute Dizziness and Vertigo. The Journal of Emergency Medicine, 50 (4), 617-628. doi: 10.1016/j.jemermed.2015.10.040

3. Lee, S.-H., Kim, J.-S. (2015). Acute Diagnosis and Management of Stroke Presenting Dizziness or Vertigo. Neurologic Clinics, 33 (3), 687-698. doi: 10.1016/j.ncl.2015.04.006

4. Abdulina, O. V. (2008). Frequency, causes, differential diagnosis, treatment and prognosis of acute vestibular vertigo in the emergency neurology. Moscow, 32.

5. Park, H., Kim, H., Cha, M., Koh, I. (2013). Vertigo. Yonsei Med J., 54 (6), 1538-1541.

6. Alekseeva, N. S. (2005). Lack of blood flow in the vertebrobasilar system and peripheral cochleovestibular syndromes. Atmosphere-Nervous Diseases, 1, 20-24.

7. Caplan, L. R., Wityk, R. J., Glass, T. A. et. al. (2004). New England Medical Center Posterior Circulation Registry. Ann. Neurol, 56, 389-398.

8. Newman-Toker, D. E., Hsieh, Y.-H., Camargo, C. A., Pelletier, A. J., Butchy, G. T., Edlow, J. A. (2008). Spectrum of Dizziness Visits to US Emergency Departments: Cross-Sectional Analysis From a Nationally Representative Sample. Mayo Clinic Proceedings, 83 (7), 765-775. doi: 10.4065/83.7.765

9. Kerber, K. A., Brown, D. L., Lisabeth, L. D., Smith, M. A., Morgenstern, L. B. (2006). Stroke Among Patients With Dizziness, Vertigo, and Imbalance in the Emergency Department: A Population-Based Study. Stroke, 37 (10), 2484-2487. doi: 10.1161/01.str.0000240329.48263.0d

10. Zamergrad, M. V. (2015). Age-related aspects of diagnosis and treatment of vertigo. Moscow, 243.
11. Parfenov, V. A., Bestuzhev, N. V. (2012). Diagnosis and treatment of vertigo in outpatients. Doctor, 12, 18-21.

12. Parfenov, V. A., Zamergrad, M. V., Melnikov, O. A. (2011). Vertigo: Diagnosis and Treatment, common diagnostic mistakes. Moscow: Medical Information Agency, 192.

13. Zhuravleva, M. V. (2011). Modern aspects of treatment of vestibular and coordination disorders. Consilium Medicum Ukraina, 2, 22-26.

14. Parfenov, V. A., Abdulina, O. V., Zamergrad, M. V. (2005). Peripheral vestibulopathy under the guise of stroke. Journal of Neurology, 6, 28-32.

15. Parfenov, V. A., Zamergrad, M. V., Melnikov, O. A., Batysheva, T. T. (2011). Vertigo. Guidelines. Medical News Agency. Moscow, 14.

16. Yavorskaya, V. A., Hvisyuk, V. V., Cooper, O. B. et. al. (2015). Clinical and pathologic comparison of different subtypes of ischemic stroke. Ukrainsky News of Psihonevrology, $23,53-57$.

17. Treschinskaya, M. A. (2008). Modern possibilities of the complex therapy of hypertensive encephalopathy. News of Medicine and Pharmacy in Ukraine, 2 (233).

18. Oshchepkova, E. V. (2004). Hypertensive encephalopathy. Consilium Medicum, 3 (3).

19. Homazyuk, T. A., Egorov, K. Y. (2010). General practice. Health Protection of Ukraine XXI century, 3 (14), 25-26.

20. Howell Collie, M. J., Ramsey, A. R. (2014). Differentiating Benign Paroxysmal Positional Vertigo From Other Causes of Dizziness. The Journal for Nurse Practitioners, 10 (6), 393-400. doi: 10.1016/j.nurpra.2014.03.008

Рекомендовано до публікаиії д-р мед. наук Дубенко О. Е. Дата надходження рукопису 25.05.2016

Svitlana Fedorchenko, Postgraduate student, Department of neuropathology and neurosurgery, Kharkiv Medical academy of Postgraduate Education, Amosova str., 58, Kharkiv, Ukraine, 61176

E-mail: svetlana221285@gmail.com 